Article

\title{
Household Food Insecurity Is Associated with Adverse Mental Health Indicators and Lower Quality of Life among Koreans: Results from the Korea National Health and Nutrition Examination Survey 2012-2013
}

\author{
Hye-Kyung Chung ${ }^{1,+}$, Oh Yoen Kim ${ }^{2,+}$, So Young Kwak ${ }^{3}$, Yoonsu Cho ${ }^{3}$, Kyong Won Lee ${ }^{3}$ \\ and Min-Jeong Shin ${ }^{3, *}$ \\ 1 Severance Institute for Vascular and Metabolic Research, Yonsei University College of Medicine, Seoul 03722, \\ Korea; chk@yuhs.ac \\ 2 Department of Food Science and Nutrition, Dong-A University, Busan 49315, Korea; oykim@dau.ac.kr \\ 3 Department of Public Health Sciences, BK21PLUS Program in Embodiment, Health-Society Interaction, \\ Graduate School, Korea University, Seoul 02841, Korea; kwaksy92@daum.net (S.Y.K.); \\ pennae@korea.ac.kr (Y.C.); chirstkw@naver.com (K.W.L.) \\ * Correspondence: mjshin@korea.ac.kr; Tel.: +82-2-3290-5643; Fax: +82-2-940-2849 \\ $\dagger$ These authors contributed equally to this work.
}

Received: 5 August 2016; Accepted: 9 December 2016; Published: 16 December 2016

\begin{abstract}
Food insecurity is an ongoing public health issue and contributes to mental health status. We investigated whether food insecurity is associated with inadequate nutrient intake and whether it affects mental health indicators (perceived stress/experience of depressive symptom/suicidal ideation) and quality of life (QOL) among Koreans $(n=5862,20-64$ years) using data from the Korea National Health and Nutritional Examination Survey (2012-2013). Household food security status was categorized as "food-secure household", "food-insecure household without hunger", and "food-insecure household with hunger". Data on food insecurity, sociodemographic factors, nutrient intake, mental health indicators, and QOL were used. A logistic regression model was conducted to determine odds ratios (ORs) for psychological health. A greater proportion of food-insecure participants were nutritionally deficient compared with expectations of the 2015 Korean Dietary Reference Intakes. These deficiencies were generally higher in both "food-insecure household" groups. Both "food-insecure household" groups, particularly the "food-insecure household with hunger" group showed significantly adverse mental health status (ORs: 1.52-3.83) and lower QOL (ORs: 1.49-3.92) than did the "food-secure household" group before and after adjusting for sex, age, education, household income, smoking/alcohol consumption, physical activity, marital status, and receiving food assistance. In conclusion, food insecurity may be significantly associated with adverse mental health indicators and decreased QOL in young/middle-aged Koreans.
\end{abstract}

Keywords: public health; food supply; quality of life; mental health indicators; Korean

\section{Introduction}

Across the world, the number of hungry people is still unacceptably high, and approximately 800 million people do not eat enough food to live and an active and healthy life [1]. Therefore, food insecurity (i.e., uncertainty of having, or inability to acquire, enough food because of insufficient money or other resources) is considered an ongoing public health issue in both developed and developing countries [2,3]. The majority of hungry people live in developing countries, and $12.9 \%$ of the people in these regions remain chronically undernourished [1]. Despite remarkable economic development, 
the prevalence of food insecurity was as high as 14.3\% among Americans in 2013 [4]. In Korea, a recent study using data from The Fifth Korea National Health and Nutrition Examination Survey (KNHANES V-3, 2012, Korea Centers for Disease Control and Prevention) reported that the prevalence of food insecurity was $11.3 \%$ among Korean adults [5].

Many studies have reported the associations between food insecurity and unfavorable health outcomes [5-11]. Food insecurity can cause malnutrition due to inadequate nutrient intake [5,6]. In addition, food insecurity is related to various chronic diseases, such as obesity [7], diabetes [8,9], hypertension [8], asthma [10], and cancer [11]. However, most studies have focused on socioeconomically vulnerable groups, such as children or low-income populations $[6,7,10,11]$. Therefore, an analysis of nationwide data is needed for a comprehensive understanding of how food insecurity has contributed to chronic diseases.

Recently, it has been proposed that food insecurity is related to mental health problems such as mood disorders and depressive symptoms [12-15]. Moreover, food insecurity was significantly more prevalent in adults with mood disorders compared to those without mood disorders $(7.3 \%$ in the general population vs. $36.1 \%$ in those with mood disorders, $p<0.001$ ) [12], and a dose-response relationship between food insecurity and depressive symptoms existed (odds ratio $(\mathrm{OR})=3.42$, 95\% confidence interval (CI): 2.61-4.49) [13]. The Veterans Aging Cohort Study, which was performed on human immunodeficiency virus (HIV)-infected and uninfected veterans, conducted in 8 regions of the United States of America (Atlanta, Georgia; Baltimore, Maryland; Bronx, New York; Manhattan/Brooklyn, New York; Houston, Texas; Los Angeles, California; Pittsburgh, Pennsylvania; and Washington, District of Columbia) demonstrated that food insecurity was associated with poor medical health, with increases in reported conditions such as depression $(\mathrm{OR}=3.00,95 \% \mathrm{CI}$ : 2.60-3.46) [14]. Furthermore, food insecurity was also associated with mental health status in children, adolescents and individuals with the human immunodeficiency virus [15-17]. A longitudinal study also suggested that food insecurity affected cognitive performance in elementary students [15]. Even though food insecurity has emerged as a contributing factor for mental health status, there is limited information regarding the relationship between food insecurity and mental health status in Korean adults. In addition to these mental health associations, several previous studies have demonstrated the relationship between food insecurity and poor quality of life (QOL) in women and ethnic minority patients with cancer $[18,19]$. Since it is a highly competitive society, Korea has a high rate of suicide and depression symptoms [20]. Therefore, the identification of contributing factors associated with mental health status and QOL is needed to relieve the mental health problems and improve the QOL of Koreans. Consequently, we used representative data from a nationwide survey to investigate whether food insecurity is associated with inadequate nutrient intake, and if it negatively affects the mental health indicators and QOL of young and middle-aged Koreans.

\section{Methods and Materials}

\subsection{Study Population}

This study was based on data from the KNHANES (2012-2013), which is a cross-sectional and nationally representative survey. The KNHANES is conducted triannually: KNHANES I (1998), KNHANES II (2002), and KNHANES III (2005); however, the more recent surveys have been conducted annually: KNHANES IV (2007-2009), KNHANES V (2010-2012), and KNHANES VI-1 (2013). The health interview questionnaire consists of household and individual-based components collected by using self-administration or face-to-face interview methods. The household component contains information provided by an adult respondent aged $\geq 19$ years and includes demographic variables such as income. For the sampling extraction method, 20 households from each of the 192 primary survey units were selected randomly using a stratified, multistage probability cluster sampling method that considered geographical area, age, and sex. In the selected households, household members aged over 1 year were targeted; both cohorts—8058 participants in the 2012 survey and 
8018 participants in the 2013 survey-were included in this study (response rates $=80.0 \%$, and 79.3\%, respectively). The KNHANES comprises health interviews, health examinations, and a nutrition survey that were conducted by trained dietitians, medical staff, and interviewers using global standard protocols. The KNHANES collects several variables regarding participants' demographic, social, health, and nutritional status from each component survey described above: the health interview, health examination and nutrition survey. Among the 16,076 participants, for this study we limited the analyses to adults aged 20-64 years. We excluded 1604 participants who were missing data on the following: food security questionnaire $(n=622)$, the mental health questionnaire $(n=979)$, and the QOL indices $(n=3)$. Additionally, we excluded 1216 participants who were diagnosed with chronic diseases including stroke, coronary artery disease, tuberculosis, type 2 diabetes mellitus, thyroid disease, cancer, renal failure, and liver cirrhosis to eliminate factors affecting household food security, mental health indicators, or QOL. We further excluded 534 participants whose sampling weighting information did not exist [21]. After all exclusions, 5862 participants (2278 men and 3584 women) were included for final statistical analysis (Figure 1). The KNHANES was approved by the institutional review board of the Korea Centers for Disease Control and Prevention (2012-01EXP-01-2C, 2013-07CON-03-4C). All survey participants provided informed written consent.

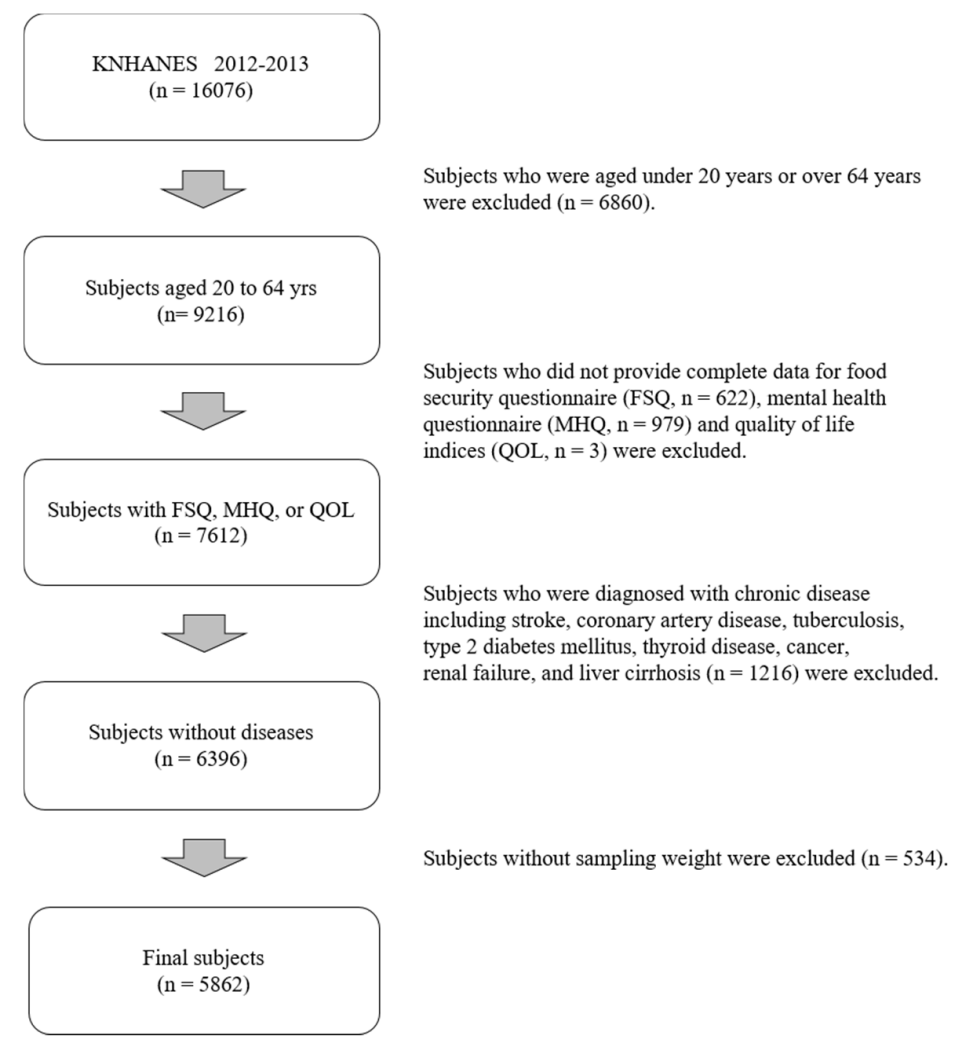

Figure 1. Flowchart of study population. FSQ: food security questionnaire; MHQ: metal health questionnaire; QOL: quality of life.

\subsection{Participants' General Characteristics}

We obtained sociodemographic and anthropometric data from the KNHANES V (2012) and VI (2013). Sociodemographic data included sex, age, education level, household income, smoking status, alcohol use, physical activity, and marital status. Education level was classified into four categories: elementary school or less, middle school, high school, or university or higher. Household income was divided into quartiles for lowest, lower-middle, upper-middle, or highest. Those who had smoked more than five packs of cigarettes (100 cigarettes) during their lifetime and those who smoked daily 
or occasionally were defined as "current smokers" based on the answer regarding their lifetime and current smoking status. In addition, a current smoker who consumes more than 20 cigarettes per day was considered a "heavy smoker". Regarding alcohol consumption, those who had experience consuming alcohol and a drinking frequency of more than once a month were categorized as "current alcohol users". In addition, those who drink at least 5 glasses (man) or 2 glasses (woman) at a time, and more than twice per week were categorized as "high-risk alcohol consumers". Those who did not have any drinking experience or drank less than once a month were categorized as "not current alcohol users". Physical activity was assessed using self-reported data based on Korean version of condensed International Physical Activity Questionnaire whose validity and reliability was confirmed in the previous study [22]. Physical activity was divided into "exercise" or "no exercise". Those who participated in any of these physical activities were referred to as the "exercise" group: vigorous physical activity for at least 20 min for more than 3 days per week or, moderate physical activity, or walking for at least $30 \mathrm{~min}$ for more than 5 days per week. On the other hand, due to the nature of the survey tool, it is not possible to distinguish between disabled and nondisabled participants. Marital status was divided into three groups: "never married" for single; "currently married (including cohabiting)"; and "formerly married" for separated, divorced, or widowed participants. Recipients of help from food assistance program were defined as those who were recently supported by the NutriPlus program, a meal service program for the elderly at a senior welfare center, a home-delivered meal service program, or a lunchbox program for children during school vacation for one year. Anthropometric measurements were conducted by trained staff members at a mobile examination center. Waist circumference (WC) was measured at midway between the rib cage and the iliac crest to the nearest $0.1 \mathrm{~cm}$ after breathing out normally. The measurement was performed once using controlled tapeline. Body mass index (BMI) was calculated as weight divided by the square of the height.

\subsection{Dietary Assessment}

The diet survey was conducted by dietitians using the face-to-face interview at participants' homes. Daily energy and nutrient intakes were obtained from the $24 \mathrm{~h}$ dietary recall method and estimated using the Korean Foods and Nutrients Database of the Rural Development Administration [23,24]. The absolute intakes of energy and nutrients from a $24 \mathrm{~h}$ dietary recall were used to estimate the proportions of energy intake deficiency (i.e., energy intake less than $75 \%$ of the estimated energy requirement) and nutrient intake deficiency (i.e., nutrient intake less than the estimated average requirement, the adequate intake, or the acceptable macronutrient distribution) by age and sex [25].

\subsection{Household Food Security}

Household food insecurity was surveyed by using one questionnaire in KNHANES until 2011. However, the 18-item questionnaire was recently (since 2012) added to the survey based on the U.S. Household Food Security/Hunger Survey Module to estimate food insecurity in multilateral aspects. In this study, we used data surveyed from the recently developed questionnaire including the newly added 18-item questionnaire [5,26]. The 18-item questionnaire was composed of 3 household-referenced questions, 7 adult-referenced questions, and 8 child-referenced questions. The questionnaire was completed by a major food purchaser in each household. A score of 1 was assigned to affirmative responses to food-insecure conditions and a score of 0 to all other responses in each questionnaire. The sum of the scores was used to categorize household food security status into 4 groups: food-secure household (a score of $0-2$, regardless of having children), food-insecure household without hunger (a score of 3-7 with children or a score of 3-5 without children), moderate food-insecure household with hunger (a score of 8-12 with children or a score of 6-8 without children), and severe food-insecure household with hunger (a score of 13-18 with children or a score of 9-10 without children). As the number of participants in "severe food-insecure household with hunger" group was low, the "moderate food-insecure household with hunger" and "severe food-insecure household with hunger" groups were merged into a single "food-insecure household with hunger" 
group. Finally, our groups for household food security status were classified as follows: "food-secure household", "food-insecure household without hunger", and "food-insecure household with hunger".

\subsection{Mental Health Indicators and Quality of Life}

Both mental health and QOL data were obtained from self-administered health questionnaires. The validity of the QOL questionnaire was verified in previous Korean studies [27]. For the questionnaire on mental health indicators, although there was a lack of demonstration of validity for Koreans, several previous studies used the questionnaire on mental health indicators for their analyses in Korean [28-30]. In the questionnaires for mental health indicators, perceived stress, experience of depressive symptoms, and suicidal ideation were used and answered as binary variables: "yes" or "no". For perceived stress, those who reported feeling very strong or strong levels in regular life were categorized as "yes", and feeling somewhat or a little stressed were categorized as "no". Regarding experience of depressive symptoms, participants who reported feeling more than two weeks of continuous sadness or despair enough to disturb their usual life over the past year were regarded as "yes". Suicidal ideation was determined based on the response to a question concerning suicidal thoughts over the past year. The EuroQoL five-dimension questionnaire (EQ-5D) developed by the EuroQoL Group was used to assess QOL. The EQ-5D comprises five dimensions: exercise ability, self-management, daily activities, pain/discomfort, and anxiety/depression. In each dimension, respondents made a choice that described their status among three categories: "no problem", "some problem", or "severe problem". Based on their responses, those who had some problem or a severe problem were categorized as "problem" and those who had no problem were categorized as "no problem".

\subsection{Statistical Analysis}

To represent the Korean population, a complex sample with applied sample weight was prepared for analysis. Statistical analysis was performed using IBM SPSS Statistics 21.0 (IBM Company, Armonk, NY, USA). Participants' general characteristics were described as percentages and numbers for categorical variables, or as mean \pm standard error for continuous variables. A chi-square test and one-way analysis of variance (ANOVA) were used to determine statistical difference in categorical and continuous variables, respectively. ORs and 95\% CIs for mental health indicators and QOL were calculated using a logistic regression model. All analyses were conducted under two models: one without adjustment and one with adjustment (general linear model) for sex, age, education level, household income, smoking status, alcohol use, physical activity, marital status, and recipients of food assistance, which were proposed as confounding factors such as age, sex, BMI, marital status, education, income, alcohol behavior, smoking status, and activity levels by previous research [31-39] and the results from our study. However, in the analysis of ORs for daily activity, physical activity as a covariate was excluded from adjusted model due to collinearity ( $p<0.05$ was considered significant).

\section{Results}

\subsection{Participants' Characteristics}

Participants' basic characteristics per household food security status are shown in Table 1. In all, $7.66 \%$ were in the food insecurity group. The number of participants was the highest in the "food-secure household" group $(n=5413)$ and the lowest in the "food-insecure household with hunger" group $(n=68)$. Participants from the "food-insecure household with hunger" group were less educated, earned less household income, and currently smoked more; participants from the "food-secure household" group drank more compared with other groups $(p<0.05)$. Participants who were single or alone after marriage were prevalent in the "food-insecure household with hunger" group, and those with a married status were more prevalent in the "food-secure household" group compared to the other groups $(p<0.001)$. The proportion of receiving help from a food assistance program was 
higher in the "food-insecure household with hunger" group compared to the other groups $(p<0.001)$. In addition, those who had poor mental health indicators including perceived stress, depressive symptom, and suicidal ideation were more represented in the "food-insecure household with hunger" group than the other groups $(p<0.001)$. Those with low QOL (exercise ability, self-management, daily activity, pain/discomfort, and anxiety/depression) were more represented in the "food-insecure household with hunger" group than the other groups $(p<0.001)$.

Table 1. General characteristics of participants per types of household food security.

\begin{tabular}{|c|c|c|c|c|}
\hline & $\begin{array}{c}\text { Food-Secure } \\
\text { Household } \\
(n=5413)\end{array}$ & $\begin{array}{c}\text { Food-Insecure } \\
\text { Household without } \\
\text { Hunger }(n=381)\end{array}$ & $\begin{array}{c}\text { Food-Insecure } \\
\text { Household with } \\
\text { Hunger }(n=68)\end{array}$ & $p \ddagger$ \\
\hline Male $\%,(n) *$ & $39.2(2120)$ & $34.4(131)$ & $39.7(27)$ & 0.146 \\
\hline Age (year) ${ }^{+}$ & $40.3 \pm 0.2$ & $40.1 \pm 0.7$ & $40.9 \pm 1.8$ & 0.842 \\
\hline waist circumference $(\mathrm{cm})$ & $79.9 \pm 0.2$ & $80.3 \pm 0.7$ & $80.6 \pm 1.3$ & 0.751 \\
\hline $\begin{array}{l}\text { Body mass index }\left(\mathrm{kg} / \mathrm{m}^{2}\right) \\
\text { Education } \%,(n)^{1}\end{array}$ & $23.7 \pm 0.1$ & $24.0 \pm 0.3$ & $23.6 \pm 0.5$ & 0.510 \\
\hline$\leq$ Elementary school & $7.4(550)$ & $15.0(57)$ & $32.4(22)$ & $<0.001$ \\
\hline$\leq$ Middle school & $7.0(435)$ & $10.8(41)$ & $14.7(10)$ & \\
\hline$\leq$ High school & $44.2(2168)$ & $49.1(187)$ & $30.9(21)$ & \\
\hline$\geq$ University & $41.5(2256)$ & $25.2(96)$ & $22.1(15)$ & \\
\hline \multicolumn{5}{|l|}{ Income $\%,(n)^{1}$} \\
\hline Lowest & $6.7(362)$ & $19.8(85)$ & $48.9(33)$ & $<0.001$ \\
\hline Lower middle & $24.6(1295)$ & $44.8(165)$ & $34.5(21)$ & \\
\hline Upper middle & $32.5(1717)$ & $25.8(98)$ & $13.3(11)$ & \\
\hline Highest & $36.3(2004)$ & $9.7(32)$ & $3.4(3)$ & \\
\hline Current smokers \%, $(n)$ & $25.4(1375)$ & $30.4(116)$ & $36.8(25)$ & 0.035 \\
\hline Current drinkers $\%,(n)$ & $62.3(3372)$ & $53.3(203)$ & $58.81(40)$ & 0.010 \\
\hline Physical activity \%, $(n)$ & $47.9(2593)$ & $47.0(179)$ & $44.1(30)$ & 0.851 \\
\hline \multicolumn{5}{|l|}{ Marital status \%, $(n)^{1}$} \\
\hline Single & $27.5(1020)$ & $27.7(82)$ & $31.7(16)$ & $<0.001$ \\
\hline Married & $68.2(4105)$ & $56.9(234)$ & $38.6(30)$ & \\
\hline Married (alone) & $4.3(278)$ & $15.4(65)$ & $29.7(22)$ & \\
\hline Food assistance $\%,(n)$ & $1.0(54)$ & $4.7(18)$ & $8.8(6)$ & $<0.001$ \\
\hline \multicolumn{5}{|l|}{ Mental health } \\
\hline Perceived stress \%, $(n)$ & $24.4(1321)$ & $33.6(128)$ & $41.2(28)$ & $<0.001$ \\
\hline Depressive symptom $\%,(n)$ & $9.4(09)$ & $15.0(57)$ & $38.2(26)$ & $<0.001$ \\
\hline Suicidal ideation $\%,(n)$ & $6.9(373)$ & $11.5(44)$ & $27.9(19)$ & $<0.001$ \\
\hline \multicolumn{5}{|l|}{ Quality of life } \\
\hline Exercise ability \%, $(n)$ & $5.3(287)$ & $13.4(51)$ & $25.0(17)$ & $<0.001$ \\
\hline Self-management $\%,(n)$ & $1.1(60)$ & $1.8(7)$ & $8.8(6)$ & $<0.001$ \\
\hline Daily activity $\%,(n)$ & $3.1(168)$ & $5.8(22)$ & $22.1(15)$ & $<0.001$ \\
\hline Pain/discomfort \%, $(n)$ & $16.2(877)$ & $22.8(87)$ & $33.8(23)$ & $<0.001$ \\
\hline Anxiety/depression \%, $(n)$ & $8.3(449)$ & $15.2(58)$ & $30.9(21)$ & $<0.001$ \\
\hline
\end{tabular}

* The values of male, education, income, current smokers, current drinkers, physical activity, marital status, recipients of food assistance, mental health indicators (perceived stress, depressive symptom, and suicidal ideation), and quality of life variables (exercise ability, self-management, daily activity, pain/discomfort, and anxiety/depression) are represented as the percentage of total participants. ${ }^{+}$The values of age, waist circumference, and body mass index are represented as mean \pm standard error. $\ddagger$ Statistical differences were determined using general linear model, complex samples crosstabs statistics for categorical variables ( $p$-value $<0.05) .{ }^{1}$ Total number in some variables can be different from the number of total subjects due to missing values.

Additionally, percentages of study subjects who had deficient intakes of energy and nutrients compared with the 2015 Korean Dietary Reference Intakes (KDRIs) were generally higher in "food-insecure household" groups, particularly "food-insecure household with hunger" group than "food-secure household" group (Table 2). Precisely, energy deficiency was defined as energy intake less than $75 \%$ of the estimated energy requirement according to sex and age for Koreans. Other 
nutrient deficiency was defined as nutrient intake less than the acceptable macronutrient distribution, the estimated average requirement or the adequate intake according to sex and age for Koreans.

Table 2. Proportion of participants who were energy and nutrient deficient when compared with the 2015 Korean Dietary Reference Intakes (KDRIs) per household food security status.

\begin{tabular}{|c|c|c|c|c|}
\hline Variables & $\begin{array}{c}\text { Food-Secure } \\
\text { Household } \\
(n=5413)\end{array}$ & $\begin{array}{c}\text { Food-Insecure } \\
\text { Household without } \\
\text { Hunger }(n=381)\end{array}$ & $\begin{array}{l}\text { Food-Insecure } \\
\text { Household with } \\
\text { Hunger }(n=68)\end{array}$ & $p$-Value \\
\hline Energy ${ }^{1}$ & $28.1 \pm 0.8$ & $31.7 \pm 3.1$ & $43.7 \pm 6.1$ & 0.029 \\
\hline Protein 2 & $9.60 \pm 0.5$ & $8.70 \pm 1.8$ & $8.40 \pm 4.5$ & 0.868 \\
\hline Protein ${ }^{3}$ & $18.3 \pm 0.7$ & $23.1 \pm 2.7$ & $34.7 \pm 6.6$ & 0.003 \\
\hline Fiber ${ }^{3}$ & $97.6 \pm 0.3$ & $98.3 \pm 0.7$ & $98.9 \pm 1.1$ & 0.567 \\
\hline Calcium $^{3}$ & $66.1 \pm 0.8$ & $70.7 \pm 2.9$ & $86.4 \pm 3.4$ & 0.002 \\
\hline Phosphorous ${ }^{3}$ & $7.80 \pm 0.4$ & $13.1 \pm 2.1$ & $24.5 \pm 6.6$ & $<0.001$ \\
\hline Iron $^{3}$ & $19.6 \pm 0.7$ & $24.9 \pm 2.7$ & $29.9 \pm 6.1$ & 0.018 \\
\hline Sodium ${ }^{4}$ & $6.5 \pm 0.4$ & $8.60 \pm 1.8$ & $13.0 \pm 4.2$ & 0.072 \\
\hline Potassium 4 & $66.0 \pm 0.8$ & $67.9 \pm 2.9$ & $84.7 \pm 4.6$ & 0.017 \\
\hline Vitamin $\mathrm{A}^{3}$ & $39.6 \pm 0.8$ & $46.7 \pm 3.2$ & $55.9 \pm 7.1$ & 0.006 \\
\hline Vitamin $\mathrm{B} 1^{3}$ & $17.1 \pm 0.7$ & $25.4 \pm 3.2$ & $23.8 \pm 5.5$ & 0.003 \\
\hline Vitamin B2 ${ }^{3}$ & $41.3 \pm 0.8$ & $45.7 \pm 3.3$ & $60.2 \pm 7.3$ & 0.023 \\
\hline Niacin ${ }^{3}$ & $24.5 \pm 0.7$ & $37.2 \pm 3.4$ & $46.1 \pm 7.7$ & $<0.001$ \\
\hline Vitamin $C^{3}$ & $47.5 \pm 1.0$ & $59.8 \pm 2.9$ & $68.6 \pm 6.4$ & $<0.001$ \\
\hline
\end{tabular}

All values are presented as the percentage \pm standard error; Statistical differences were determined using complex samples crosstabs statistics ( $p$ value $<0.05) ;{ }^{1}$ energy deficiency was defined as energy intake less than $75 \%$ of the estimated energy requirement per sex and age for Koreans; ${ }^{2}$ nutrient deficiency was defined as nutrient intake less than the acceptable macronutrient distribution per sex and age for Koreans; ${ }^{3}$ nutrient deficiency was defined as nutrient intake less than the estimated average requirement per sex and age for Koreans; ${ }^{4}$ nutrient deficiency was defined as nutrient intake less than the adequate intake per sex and age for Koreans.

\subsection{Odds Ratios for Mental Health Indicators per Types of Household Food Insecurity}

To examine the association between household food insecurity status and mental health indicators, a logistic regression was conducted. As shown in Table 3, household food insecurity status was significantly associated with mental health before and after adjustment. Compared with the "food-secure household", both "food-insecure household without hunger" and "food-insecure household with hunger" had poor mental health indicators; both groups showed positive associations with perceived stress before adjustment $(\mathrm{OR}=1.56,95 \% \mathrm{CI}: 1.19-2.06, p=0.001 ; \mathrm{OR}=2.15,95 \% \mathrm{CI}$ : 1.26-3.68, $p=0.005$, respectively) and after adjustment $(\mathrm{OR}=1.52,95 \% \mathrm{CI}: 1.15-2.01, p=0.003$; $\mathrm{OR}=1.96,95 \% \mathrm{CI}: 1.08-3.53, p=0.026$, respectively). They also showed positive associations with depressive symptoms in the unadjusted model (OR = 1.68, 95\% CI: 1.20-2.35, $p=0.003$; OR = 5.77, 95\% CI: 3.29-10.1, $p<0.001$, respectively), however, after adjustment, only the "food-insecure household with hunger" group was significant (OR $=3.64,95 \%$ CI: 2.17-6.08, $p<0.001)$. In addition, both "food-insecure household without hunger" and "food-insecure household with hunger" showed significant associations with suicidal ideation before adjustment (OR = 1.75, 95\% CI: 1.13-2.72, $p=0.013$; $\mathrm{OR}=5.24,95 \%$ CI: 2.77-9.94, $p<0.001$, respectively), however, after adjustment, only "food-insecure household with hunger" showed a significant association with suicidal ideation $(\mathrm{OR}=3.83,95 \% \mathrm{CI}$ : 2.02-7.23, $p<0.001)$. 
Table 3. Odds ratios and $95 \%$ confidence intervals for the mental health indicators per types of household food security.

\begin{tabular}{|c|c|c|c|c|c|}
\hline & $\begin{array}{c}\text { Food-Secure } \\
\text { Household }(n=5413)\end{array}$ & $\begin{array}{l}\text { Food-Insecure Household } \\
\text { without Hunger }(n=381)\end{array}$ & $p$-Value & $\begin{array}{l}\text { Food-Insecure Household } \\
\text { with Hunger }(n=68)\end{array}$ & $p$-Value \\
\hline \multicolumn{6}{|l|}{ Perceived stress * } \\
\hline Unadjusted $^{+}$ & 1.00 (ref) & $1.56(1.19-2.06)$ & 0.001 & $2.15(1.26-3.68)$ & 0.005 \\
\hline Multivariable adjusted ${ }^{1}$ & 1.00 (ref) & $1.52(1.15-2.01)$ & 0.003 & $1.96(1.08-3.53)$ & 0.026 \\
\hline \multicolumn{6}{|l|}{ Depressive symptom } \\
\hline Unadjusted $^{+}$ & 1.00 (ref) & $1.68(1.20-2.36)$ & 0.003 & $5.77(3.29-10.1)$ & $<0.001$ \\
\hline \multicolumn{6}{|l|}{ Suicidal ideation } \\
\hline Unadjusted $^{\dagger}$ & 1.00 (ref) & $1.75(1.13-2.72)$ & 0.013 & $5.24(2.77-9.94)$ & $<0.001$ \\
\hline Multivariable adjusted $^{1}$ & 1.00 (ref) & $1.33(0.83-2.14)$ & 0.234 & $3.83(2.02-7.23)$ & $<0.001$ \\
\hline
\end{tabular}

${ }^{*}$ Values are presented as odds ratios (95\% confidence intervals); ${ }^{\dagger}$ differences were tested using unadjusted complex samples logistic regression analysis; ${ }^{1}$ differences were tested using multivariable-adjusted complex sample logistic regression analysis after adjusting for sex, age, income, education, alcohol use, smoking status, physical activity, marital status, and recipients of food assistance.

\subsection{Odds Ratios for the Quality of Life per Types of Household Food Security}

The ORs for QOL per household food security status are presented in Table 4. All QOL indices were associated with household food security status. Compared with the "food-secure household" group, both "food-insecure household without hunger" and "food-insecure household with hunger" groups showed significantly higher ORs for decreased exercise ability and increased anxiety/depression before and after the adjustment. For self-management, the "food-insecure household with hunger" group had significantly higher ORs than the "food-secure household" group in the unadjusted model (OR $=8.23,95 \%$ CI: 2.90-23.4, $p<0.001$ ). In addition, the "food-insecure household without hunger" and "food-insecure household with hunger" showed significantly higher ORs for decreased daily activity than the "food-secure household" group before adjustment; however, after adjustment, only in the "food-insecure households with hunger" group was significant (OR $=3.92$, 95\% CI: 1.87-8.20, $p<0.001)$. Regarding pain/discomfort, both "food-insecure household without hunger" and "food-insecure household with hunger" group showed significantly higher ORs than did the "food-secure household" group; however, this was only true in the unadjusted model $(p<0.005)$.

Table 4. Odds ratios and 95\% confidence intervals for the quality of life per types of household food security.

\begin{tabular}{|c|c|c|c|c|c|}
\hline & $\begin{array}{c}\text { Food-Secure } \\
\text { Household }(n=5413)\end{array}$ & $\begin{array}{l}\text { Food-Insecure Household } \\
\text { without Hunger }(n=381)\end{array}$ & $p$-Value & $\begin{array}{l}\text { Food-Insecure Household } \\
\text { with Hunger }(n=68)\end{array}$ & $p$-Value \\
\hline \multicolumn{6}{|l|}{ Decreased Exercise ability * } \\
\hline Unadjusted $^{+}$ & 1.00 (ref) & $2.78(1.86-4.14)$ & $<0.001$ & $5.93(3.15-11.2)$ & $<0.001$ \\
\hline Multivariate adjusted $^{1}$ & 1.00 (ref) & $2.22(1.45-3.40)$ & $<0.001$ & $3.22(1.78-5.82)$ & $<0.001$ \\
\hline \multicolumn{6}{|l|}{ Self-management } \\
\hline Unadjusted $^{\dagger}$ & 1.00 (ref) & $1.68(0.77-3.66)$ & 0.191 & $8.23(2.90-23.4)$ & $<0.001$ \\
\hline Multivariate adjusted ${ }^{1}$ & 1.00 (ref) & $1.15(0.49-2.70)$ & 0.756 & $3.19(0.94-10.8)$ & 0.062 \\
\hline \multicolumn{6}{|l|}{ Decreased Daily activity } \\
\hline Unadjusted $^{\dagger}$ & 1.00 (ref) & $1.90(1.10-3.28)$ & 0.021 & $9.05(4.81-17.1)$ & $<0.001$ \\
\hline Multivariate adjusted $^{2}$ & 1.00 (ref) & $1.21(0.67-2.18)$ & 0.523 & $3.92(1.87-8.20)$ & $<0.001$ \\
\hline \multicolumn{6}{|l|}{ Pain/discomfort } \\
\hline Unadjusted $^{\dagger}$ & 1.00 (ref) & $1.54(1.13-2.08)$ & 0.006 & $2.55(1.40-4.65)$ & 0.002 \\
\hline Multivariate adjusted ${ }^{1}$ & 1.00 (ref) & $1.29(0.95-1.76)$ & 0.108 & $1.69(0.87-3.27)$ & 0.124 \\
\hline \multicolumn{6}{|l|}{ Anxiety/depression } \\
\hline Unadjusted $^{+}$ & 1.00 (ref) & $1.97(1.36-2.87)$ & $<0.001$ & $4.84(2.74-8.54)$ & $<0.001$ \\
\hline Multivariate adjusted ${ }^{1}$ & 1.00 (ref) & $1.49(1.00-2.23)$ & 0.049 & $2.63(1.52-4.55)$ & 0.001 \\
\hline \multicolumn{6}{|c|}{$\begin{array}{l}{ }^{*} \text { Values are presented as odds ratios (95\% confidence intervals); }{ }^{\dagger} \text { differences were tested using unadjusted } \\
\text { complex samples logistic regression analysis; }{ }^{1} \text { differences were tested using multivariate-adjusted complex } \\
\text { sample logistic regression analysis after adjusting for sex, age, income, education, alcohol use, smoking } \\
\text { status, physical activity, marital status, and recipients of food assistance; }{ }^{2} \text { differences were tested using } \\
\text { multivariate-adjusted complex sample logistic regression analysis after adjusting for sex, age, income, education, }\end{array}$} \\
\hline
\end{tabular}




\section{Discussion}

This study was designed to determine the effect of food insecurity on nutrient intake, mental health indicators, and quality of life. The results of this study show that food insecure participants were nutritionally deficient and showed adverse mental health status and lower quality of life. Our results are consistent with earlier findings that reported a dose-response relationship between depression and food security: the OR of depression was higher in the lowest food-secure group than the highest food-secure group ( $\mathrm{OR}=3.42,95 \% \mathrm{CI}: 2.61-4.49)$ [13]; and the food insecurity co-occurred with maternal depression (OR $=2.82,95 \% \mathrm{CI}$ : 1.62-4.93) [40] assessed by DSM-IV tool. Also, other previous studies revealed that food insecurity status change was positively associated with less depression (estimates: 0.84), assessed by composite international diagnostic interview (CIDI) [19], and demonstrated that there was strong association between food insecurity and psychological distress, assessed by the Kessler psychological distress scale (K-10) $(\mathrm{OR}=3.4,95 \%$ CI: 3.1-3.7) [41]. We observed that food-insecure young and middle-aged participants showed significantly higher ORs for perceived stress, depression symptoms, and suicidal ideation. A previous cross-sectional study reported an association between food insecurity and psychological distress in healthy men and women [40] and that food-insecure respondents experienced higher psychological distress compared to food-secure respondents in a clinical study on inpatients in a psychiatric hospital [42]. In line with this, low-income adults showed dose-response relationships between the level of food insecurity and the prevalence of depressive symptoms $[13,19,40]$. Additionally, a study using two longitudinal data sets demonstrated the relationships between food insecurity and depression in elderly adults [43]. Moreover, a cross-sectional survey on mothers of 3-year-old children found a relationship between food insecurity and anxiety disorders [40]. Another cross-sectional survey showed that food insecurity was more prevalent in adults with mood disorders than those without mood disorders [12]. Our study corroborated previous findings that food insecurity was associated with mental health indicators, even in healthy adults. Since significant associations between food insecurity and mental health indicators were maintained after adjustment for socioeconomic and lifestyle factors known to affect mental health indicators, the impact of food insecurity on mental health may be independent of these factors in this healthy population.

Food insecurity was also closely associated with lower QOL such as exercise ability and daily activity in the general population. There were relatively limited data on the relationships between food insecurity and QOL; however, an inverse association between food insecurity and QOL has been observed in women [19]. Recent studies on cancer patients also revealed that self-reported physical, functional, social, emotional well-being scores, and QOL decreased with increased levels of food insecurity [44]. The relationship between food insecurity and QOL is complicated, because QOL is composed of multilateral factors such as exercise ability, self-management, daily activities, pain/discomfort, and anxiety/depression. However, some previous studies suggested that food insecurity may affect some factors of QOL, like exercise ability and daily activity, through low-quality food intake, essential nutrient deficiencies, and poor nutritional status [45-50]. In our study, we found that the "food-insecure household" groups, particularly the "food-insecure household with hunger" group generally showed higher proportions of energy and nutrient deficiencies when compared with the 2015 KDRIs. This significantly affects mental health indicators and lowers QOL more so than it does in the "food-secure household" group.

In line with this, previous studies have documented the relationship between food intake and functional disability such as dressing, bathing, eating, and other activities [44-47]. Studies on elderly Koreans proposed that frequent consumption of dairy products, legumes, or soy products were inversely related with functional disability $[45,47]$. Dietary patterns are also associated with activities of daily living (ADL) and instrumental ADL (IADL) disability [47]. Evidence also exists for the harmful effects of food insecurity on nutrition status. Studies addressing Chinese elementary students and Brazil adolescents showed that food insecurity was closely related to malnutrition risk $[6,48]$. In our study, the proportion of participants who met the dietary reference intake for most nutrients 
were significantly lower in the "food-insecure household" groups, particularly the "food-insecure household with hunger" group, than the "food-secure household" group. Therefore, insufficient nutrition induced by food insecurity may be partly linked to lower QOL. However, in our study, the associations between food-insecurity, mental health indicators, and QOL were not compared between disabled and nondisabled participants, because we did not distinguish these differences among the KNHANES data.

Our results imply that mental health indicators and QOL are associated with food insecurity and may be improved by resolving food insecurity problems. Considering that Korea has the highest suicide rate and poor mental health status among Organization for Economic Cooperation and Development countries [49,50], active intervention by the Korean government is necessary to reduce the food insecurity problem and promote better mental health. Korea has several nutrition assistance programs such as the "NutriPlus Program", "the healthy fruit basket project", and "free meal service", which are provided for vulnerable populations [51,52]. Moreover, some previous studies reported the effectiveness of these programs for vulnerable Korean populations [51,53]. In our study, participation in the nutrition assistance program did not modify the association between food insecurity, mental health, and QOL.

Our study had several limitations as well. First, this was a cross-sectional study; therefore, we cannot explain causal relationships. Second, there was a possibility of underestimating food insecurity if respondents were reluctant to answer openly to the food insecurity questionnaire. Third, the KNHANES excluded extremely food-insecure people, such as the institution-dwelling or homeless population, because it was difficult to recruit them. Fourth, the associations between food-insecurity, mental health indicators, and QOL were not compared between disabled and nondisabled participants, because we did not distinguish these differences among the KNHANES data. Finally, the questionnaire to assess mental-health problems has not been fully validated [28], even though several previous studies have used this questionnaire [29,30]. Despite these limitations, our results have important strengths when compared to previous studies' findings. As far as we know, this is the first study demonstrating that food insecurity is a strong factor that results in adverse mental health and lower QOL in the general population of Korean adults. We analyzed a representative, large-scale data set composed of participants with homogeneous characteristics (i.e., young, middle-aged Koreans without chronic diseases). In addition, we considered various sociodemographic and health-related factors in our adjustment to minimize the possibility of confounding factors.

In conclusion, food insecurity was closely associated with insufficient nutrient intake, adverse mental health indicators, and lower QOL in young and middle-aged Korean adults. Our results provide the basic information for a health policy to prepare more effective programs to improve the mental health and QOL of individuals who have an insufficient diet.

Acknowledgments: This work was supported by Basic Science Research Program through the National Research Foundation of Korea (NRF) funded by the Ministry of Science, ICT, and future Planning (2015R1A2A1A15054758).

Author Contributions: M.J.S. conceived the study. H.K.C., O.Y.K., S.Y.K. and Y.C. developed the statistical analysis plan. S.Y.K. and Y.C. analyzed the data. H.K.C., O.Y.K. and M.J.S. prepared the first draft of manuscript. H.K.C., O.Y.K., S.Y.K., Y.C., K.W.L. and M.J.S. contributed to the writing of the manuscript. All authors reviewed and agreed on final version of the manuscript.

Conflicts of Interest: The authors declare no conflict of interest.

\section{References}

1. Food and Agriculture Organization of the United Nations; International Fund for Agricultural Development; World Food Programme. The State of Food Insecurity in the World 2015: Meeting the 2015 International Hunger Targets: Taking Stock of Uneven Progress. Available online: http://www.fao.org/3/a-i4646e.pdf (accessed on 5 May 2016).

2. Gundersen, C. Food insecurity is an ongoing national concern. Adv. Nutr. 2013, 4, 36-41. [CrossRef] [PubMed] 
3. Food and Agriculture Organization of the United Nations. An Introduction to the Basic Concepts of Food Security. Available online: http:/ /www.fao.org/docrep/013/al936e/al936e00.pdf (accessed on 7 May 2016).

4. Coleman-Jensen, A.; Gregory, C.; Singh, A. Household food security in the United States in 2013. Available online: http:/ / www.ers.usda.gov/publications/err-economic-research-report/err173.aspx (accessed on 15 June 2016).

5. Kim, H.J.; Oh, K. Household food insecurity and dietary intake in Korea: Results from the 2012 Korea National Health and Nutrition Examination Survey. Public Health Nutr. 2015, 1, 1-9. [CrossRef] [PubMed]

6. Shen, X.; Gao, X.; Tang, W.; Mao, X.; Huang, J.; Cai, W. Food insecurity and malnutrition in Chinese elementary school students. Br. J. Nutr. 2015, 18, 1-7. [CrossRef] [PubMed]

7. Shariff, Z.M.; Khor, G.L. Obesity and household food insecurity: Evidence from a sample of rural households in Malaysia. Eur. J. Clin. Nutr. 2005, 59, 1049-1058. [CrossRef] [PubMed]

8. Pérez-Escamilla, R.; Villalpando, S.; Shamah-Levy, T.; Méndez-Gómez Humarán, I. Household food insecurity, diabetes, and hypertension among Mexican adults: Results from Ensanut 2012. Salud Publica Mex 2014, 56 (Suppl. S1), s62-s70. [PubMed]

9. Seligman, H.K.; Bindman, A.; Vittinghoff, E.; Kanaya, A.M.; Kushel, M.B. Food insecurity is associated with diabetes mellitus: Results from the National Health Examination and Nutritional Examination Survey 1999-2002. J. Gen. Intern. Med. 2007, 22, 1018-1023. [CrossRef] [PubMed]

10. Kirkpatrick, S.S.; McIntyre, L.; Potestio, M. Child hunger and long-term adverse consequences for health. Arch. Pediatr. Adolesc. Med. 2010, 164, 754-762. [CrossRef] [PubMed]

11. Gany, F.; Lee, T.; Ramirez, J.; Massie, D.; Moran, A.; Crist, M.; McNish, T.; Winkel, G.; Leng, J.C. Do our patients have enough to eat? Food insecurity among urban low-income cancer patients. J. Health Care Poor Underserved 2014, 25, 1153-1168. [CrossRef] [PubMed]

12. Davison, K.M.; Kaplan, B.J. Food insecurity in adults with mood disorders: Prevalence estimates and associations with nutritional and psychological health. Ann. Gen. Psychiatry 2015, 14, 21. [CrossRef] [PubMed]

13. Leung, C.W.; Epel, E.S.; Willett, W.C.; Rimm, E.B.; Laraia, B.A. Household food insecurity is positively associated with depression among low-income supplemental nutrition assistance program participants and income-eligible nonparticipants. J. Nutr. 2015, 145, 622-627. [CrossRef] [PubMed]

14. Wang, E.A.; McGinnis, K.A.; Goulet, J.; Bryant, K.; Gibert, C.; Leaf, D.A.; Mattocks, K.; Fiellin, L.E.; Vogenthaler, N.; Justice, A.C.; et al. Food insecurity and health: Data from the Veterans Aging Cohort Study. Public Health Rep. 2015, 130, 261-268. [PubMed]

15. Howard, L. Does food insecurity at home affect non-cognitive performance at school? A longitudinal analysis of elementary student classroom behavior. Econ. Educ. Rev. 2011, 30, 157-176. [CrossRef]

16. Alaimo, K.; Olson, C.M.; Frongillo, E.A. Family food insufficiency, but not low family income, is positively associated with dysthymia and suicide symptoms in adolescents. J. Nutr. 2002, 132, 719-725. [PubMed]

17. Vogenthaler, N.S.; Hadley, C.; Lewis, S.J.; Rodriguez, A.E.; Metsch, L.R.; del Rio, C. Food insufficiency among HIV-infected crack-cocaine users in Atlanta and Miami. Public Health Nutr. 2010, 13, 1478-1484. [CrossRef] [PubMed]

18. Simmons, L.A.; Modesitt, S.C.; Brody, A.C.; Leggin, A.B. Food insecurity among cancer patients in Kentucky: A pilot study. J. Oncol. Pract. 2006, 2, 274-279. [CrossRef] [PubMed]

19. Heflin, C.M.; Siesfert, K.; Willams, D.R. Food insufficiency and women's mental health: Findings from a 3-year panel of welfare recipients. Soc. Sci. Med. 2005, 61, 1971-1982. [CrossRef] [PubMed]

20. Korean Ministry of Health and Welfare. Korea Health Statistics 2013: Korea National Health and Nutrition Examination Survey (KNHANES). Available online: http://cdc.go.kr/CDC/cms/content/mobile/14/ 28314_view.html (accessed on 25 June 2016).

21. Byeon, H.W. Comparative analysis of unweighted sample design and complex sample design related to the exploration of potential risk factors of dysphonia. J. Korea Acad. Ind. Cooperation Soc. 2012, 13, 2251-2258. [CrossRef]

22. Craig, C.L.; Marshall, A.L.; Sjöström, M.; Bauman, A.E.; Booth, M.L.; Ainsworth, B.E.; Pratt, M.; Ekelund, U.; Yngve, A.; Sallis, J.F.; et al. International physical activity questionnaire: 12-country reliability and validity. Med. Sci. Sports Exerc. 2003, 35, 1381-1395. [CrossRef] [PubMed]

23. Rural Resources Development Institute. Food Composition Table, 7th ed.; Rural Resources Development Institute: Suwon, Korea, 2006. 
24. Rural Resources Development Institute. Food Composition Table, 8th ed.; Rural Resources Development Institute: Suwon, Korea, 2011.

25. Ministry of Health and Welfare. Dietary Reference Intakes for Koreans 2015; Ministry of Health and Welfare: Sejong, Korea, 2015.

26. Kim, K.; Hong, S.A.; Kwon, S.O.; Choi, B.Y.; Kim, G.Y.; Oh, S.Y. Validation of food security measures for the Korean National Health and Nutrition Examination Survey. Korean J. Community Nutr. 2011, 16, 771-781. [CrossRef]

27. Korean Centers for Disease Control and Prevention. Validation and Reliability Evaluation for EQ-5D in Korea. Available online: http:/ /www.cdc.go.kr/CDC/info/CdcKrInfo0201.jsp?menuIds=HOME001-MNU1155MNU1083-MNU1375-MNU0025\%20\&fid=28\&q_valu=\&cid=1742\&pageNum=1 (accessed on 1 June 2016).

28. Cho, G.E.; Lim, D.H.; Baek, M.; Lee, H.; Kim, S.J.; Kang, S.W. Epidemiologic survey committee of the Korean Ophthalmological Society. Visual impairment of Korean population: Prevalence and impact on mental health. Investig. Ophthalmol. Vis. Sci. 2015, 8, 4375-4381.

29. Rim, T.H.; Lee, C.S.; Lee, S.C.; Chung, B.; Kim, S.S. Epidemiologic Survey Committee of the Korean Ophthalmological Society. Influence of visual acuity on suicidal ideation, suicide attempts, and depression in South Korea. Br. J. Ophthalmol. 2015, 99, 1112-1119. [CrossRef] [PubMed]

30. Jeon, G.S.; Jang, S.N.; Rhee, S.J.; Kawachi, I.; Cho, S.I. Gender differences in correlates of mental health among elderly Koreans. J. Gerontol. B Psychol. Sci. Soc. Sci. 2007, 62, S323-S329. [CrossRef] [PubMed]

31. Kaplan, R.M.; Anderson, J.P.; Wingard, D.L. Gender differences in health-related quality of life. Health Psychol. 1991, 10, 86-93. [CrossRef] [PubMed]

32. Mercier, C.; Péladeau, N.; Tempier, R. Age, gender and quality of life. Community Ment. Health J. 1998, 34, 487-500. [CrossRef] [PubMed]

33. Lasheras, C.; Patterson, A.M.; Casado, C. Effects of education on the quality of life, diet, and cardiovascular risk factors in an elderly Spanish community population. Exp. Aging Res. 2001, 27, 257-270. [CrossRef] [PubMed]

34. Frischknecht, U.; Sabo, T.; Mann, K. Improved drinking behavior improves quality of life: A follow-up in alcohol-dependent subjects 7 years after treatment. Alcohol. Alcohol. 2013, 48, 579-584. [CrossRef] [PubMed]

35. Teoman, N.; Ozcan, A.; Acar, B. The effect of exercise on physical fitness and quality of life in postmenopausal women. Maturitas 2004, 47, 71-77. [CrossRef]

36. Mulder, I.; Tijhuis, M.; Smit, H.A.; Kromhout, D. Smoking cessation and quality of life: The effect of amount of smoking and time since quitting. Prev. Med. 2001, 33, 653-660. [CrossRef] [PubMed]

37. Maluccio, J.A.; Palermo, T.; Kadiyala, S.; Rawar, R. Improving health-related quality of life among people living with HIV: Results from an impact evaluation of a food assistance program in Uganda. PLoS ONE 2015, 10, e0135879. [CrossRef] [PubMed]

38. Lee, S. Marital status, gender, and subjective quality of life in Korea. Dev. Soc. 1998, 27, 35-49. [PubMed]

39. Zhang, Y.; Ou, F.; Gao, S.; Gao, Q.; Hu, L.; Liu, Y. Effect of low income on health-related quality of life: A cross-sectional study in northeast China. Asia Pac. J. Public Health 2015, 27. [CrossRef] [PubMed]

40. Melchior, M.; Caspi, A.; Howard, L.M.; Ambler, A.P.; Bolton, H.; Mountain, N.; Moffitt, T.E. Mental health context of food insecurity: A representative cohort of families with young children. Pediatrics 2009, 124, e564-e572. [CrossRef] [PubMed]

41. Carter, K.N.; Kruse, K.; Blakely, T.; Collings, S. The association of food security with psychological distress in New Zealand and any gender differences. Soc. Sci. Med. 2011, 72, 1463-1471. [CrossRef] [PubMed]

42. Grisaru, N.; Kaufman, R.; Mirsky, J.; Wirztum, E. Food insecurity and mental health: A pilot study of patients in a psychiatric emergency unit in Israel. Community Ment. Health J. 2011, 47, 513-519. [CrossRef] [PubMed]

43. Kim, K.; Frongillo, E.A. Participation in food assistance programs modifies the relation of food insecurity with weight and depression in elders. J. Nutr. 2007, 137, 1005-1010. [PubMed]

44. Gany, F.; Leng, J.; Ramirez, J.; Phillips, S.; Aragones, A.; Roberts, N.; Mujawar, M.I.; Costas-Muniz, R. Health-related quality of life of food-insecure ethnic minority patients with cancer. J. Oncol. Pract. 2015, 11, 396-402. [CrossRef] [PubMed]

45. Kim, J.; Lee, Y. Frequency of dairy consumption and functional disability in older persons. J. Nutr. Health Aging 2011, 15, 795-800. [CrossRef] [PubMed]

46. Kim, J.; Lee, Y.; Lee, S.Y. Legumes and soy products consumption and functional disability in older women. Maturita 2011, 69, 268-272. [CrossRef] [PubMed] 
47. Kim, J.; Lee, Y.; Lee, S.Y.; Kim, Y.O.; Chung, Y.S.; Park, S.B. Dietary patterns and functional disability in older Korean adults. Maturitas 2013, 76, 160-164. [CrossRef] [PubMed]

48. Lopes, T.S.; Sichieri, R.; Salles-Costa, R.; Veiga, G.V.; Pereira, R.A. Family food insecurity and nutritional risk in adolescents from a low-income area of Rio de Janeiro, Brazil. J. Biosoc. Sci. 2013, 45, 661-674. [CrossRef] [PubMed]

49. Organization for Economic Co-operation and Development. How's Life? 2015, Measuring Well-Being. Available online: http://www.ifutureo.org/documentacion/hows\%20life\%202015.pdf (accessed on 20 June 2016).

50. Organization for Economic Co-operation and Development. OECD Fact Book 2013: Economic, Environmental and Social Statistics. Available online: http://www.oecd-ilibrary.org/economics/oecdfactbook-2013_factbook-2013-en (accessed on 20 June 2016).

51. Ministry of Health \& Welfare. The 1st National Nutrition Care/Management in Korea. Available online: http:/ / www.korea.kr/archive/expDocView.do?docId=32234 (accessed on 12 June 2016).

52. Ministry of Health \& Welfare. Elderly Care Service. Available online: http://www.129.go.kr/info/info04_ view.jsp?n=51 (accessed on 14 June 2016).

53. Park, S.A.; Yoon, E.Y. The effect of NutriPlus program among 1-5 years children in Daejeon Area-the improvement in nutritional status of children and nutrition knowledge and attitude of parents. Korean J. Community Nutr. 2013, 18, 1-10. [CrossRef]

(C) 2016 by the authors; licensee MDPI, Basel, Switzerland. This article is an open access article distributed under the terms and conditions of the Creative Commons Attribution (CC-BY) license (http://creativecommons.org/licenses/by/4.0/). 